\title{
Assessment of occupational exposure in a population based case-control study: comparing postal questionnaires with personal interviews
}

\author{
B M Blatter, N Roeleveld, G A Zielhuis, A L M Verbeek
}

\begin{abstract}
Background-In case-control studies, data collection on occupational exposures by means of personal interviews is usually costly and time consuming. As detailed semiquantitative information on exposure from these interviews often has to be dichotomised in the analyses due to the small numbers of exposed subjects, the question is raised whether simple postal questionnaires yield the same results for occupational exposure in epidemiological studies as job specific personal interviews.

Methods-Data on occupational exposures during pregnancy were compared from 121 women who both completed a checklist with 17 occupational exposure categories in a postal questionnaire and were personally interviewed with specific questions on exposure with details of job and task. $\kappa$ Coefficients were calculated as measures of agreement corrected for chance, and sensitivity and positive predictive values as measures of validity and usefulness, with the exposure assessment based on information from the interview as the gold standard.
\end{abstract}

Results-Values of $\kappa$ varied from 0.09 for domestic cleaning agents to 0.70 for pesticides, indicating only low to moderate agreement between the questionnaire and the interview. Sensitivity ranged from $38 \%$ to $100 \%$, with the highest values for agents used by healthcare workers. Positive predictive values were lower, between $9 \%$ and $63 \%$, which indicates that overreporting was more common than underreporting in the questionnaire.

Conclusions-These results underline the high potential for misclassification of occupational exposure in studies based on questionnaires. Therefore, postal questionnaires are not considered an alternative to job and task specific personal interviews in epidemiological studies.

(Occup Environ Med 1997;54:54-59)

Keywords: occupational exposure; questionnaires; interviews; methods

Population based case-control studies in occupational epidemiology usually involve retrospective exposure assessment of a large variety of occupations and chemical or physical agents and widely varying levels of exposure.
Exposure assessment in these studies is often based on self reported information from postal questionnaires or interviews. Currently, much attention is given to the improvement of assessment of exposure to minimise misclassification and consequently to better identify weak associations. ${ }^{1}$ Traditionally, in occupational epidemiology data have been collected by asking subjects whether they were exposed to specific agents or asking open ended generic questions. Later, more specific methods of data collection were suggested. One such method is to obtain general information on the occupation of the respondent, which is then used by chemists and industrial hygienists to infer the presence and the level of specific agents. Also, job specific questionnaires, including questions on tasks and activities, equipment, and work environment, were designed to increase the accuracy of the exposure assessment. ${ }^{2-5}$ However, this method is costly and labour intensive.

Several studies have been published on the validity of job titles and occupational histories, ${ }^{67}$ showing satisfactory validity in most cases. Validity and reliability studies of occupational exposure usually concern current exposure data and are conducted in a single type of worksite. ${ }^{89}$ Teschke et al, ${ }^{9}$ with two different questionnaire formats, compared air sampling results and observations of work patterns in a group of saw filers. Although the questionnaire with detailed prompting of chemical agents had a higher sensitivity than the open ended and partly prompted questionnaire, overall, both sensitivity and specificity were low. Therefore, the authors suggested probing about exposures estimated from the specific tasks performed as a better method.

Validity studies on retrospective exposure data derived from population based case-control studies are extremely difficult. As it is often impossible to perform measurements or retrieve company records, no gold standard is available in these studies. ${ }^{9}$ Ezkenazi and Pearson $^{10}$ compared self administered questionnaires with detailed clinical interviews by an occupational health professional and examined whether the validity could be improved through review of the postal questionnaires by an industrial hygienist. They found that the questionnaire was substantially accurate, although $\kappa$ coefficients were only presented for general exposure categories. They recommended the use of a self administered questionnaire, thoroughly reviewed by an industrial hygienist. 
We recently performed a population based case-control study on spina bifida and maternal occupational exposure, in which data were collected by detailed job specific interviews. ${ }^{11}$ Also, information on occupational exposure of the same respondents was available from postal questionnaires used in an earlier phase of the study. ${ }^{12}$ Because the numbers of exposed women were small and the levels of exposure were low, several chemical or physical agents had to be clustered into broader exposure categories. Also, qualitative instead of quantitative or semi-quantitative measurements had to be used. As a result, much of the detailed information that was collected in the interviews was lost. The question then arose whether the self administered postal questionnaire would have yielded the same results on occupational exposure as the job specific, time consuming personal interviews with additional exposure assessment by the investigators. The purpose of the present study was to investigate the degree of agreement between these two methods of assessment of occupational exposure and to examine the validity and usefulness of a postal questionnaire when the detailed interview is considered to be the gold standard.

\section{Population and methods}

The study population included 470 mothers of children with spina bifida aperta (cases) and 2350 mothers of children who had experienced a trauma capitis or meningitis or were sampled from the general population (controls). All children were born between 1 January 1980 and 31 December 1992. Data collection was carried out in two phases. Firstly, all mothers were approached for the study by post with a letter from their child's attending physician or from a municipal administrator. A letter from the investigators, a brochure with information, and a questionnaire were enclosed. The questionnaire included questions about occupational title and industry and a list with 17 chemical and physical exposure groups. For ease of completion, all questions referred to one date of interest as a proxy for the period around conception. This date was defined as the date of birth of the index child minus one year.

Detailed information on occupational exposures was collected from a subset of 121 mothers by means of personal interviews at home. The time lag between the interview

Table 1 Two by two table with formulas of proportion of agreement (agr), $\kappa$, sensitivity, positive predictive value, and McNemar's test

\begin{tabular}{|c|c|c|c|c|}
\hline & & \multicolumn{3}{|c|}{ Exposed according to interview } \\
\hline & & yes & no & \\
\hline \multirow[t]{2}{*}{ Exposed according to questionnaire: } & $\begin{array}{l}\text { Yes } \\
\text { No }\end{array}$ & $\begin{array}{l}\mathrm{a} \\
\mathrm{c}\end{array}$ & $\begin{array}{l}\mathrm{b} \\
\mathrm{d}\end{array}$ & \multirow{2}{*}{$\begin{array}{l}a+b \\
c+d \\
n\end{array}$} \\
\hline & & \multicolumn{2}{|c|}{$a+c$} & \\
\hline $\begin{array}{l}\text { Proportion of agreement }= \\
\text { Proportion of chance agreement }= \\
\kappa \text { Coefficient }= \\
\text { Sensitivity }= \\
\text { Positive predictive value }= \\
\text { McNemar's test }\left(\chi^{2}, 1 \mathrm{df}\right)=\end{array}$ & \multicolumn{4}{|c|}{ 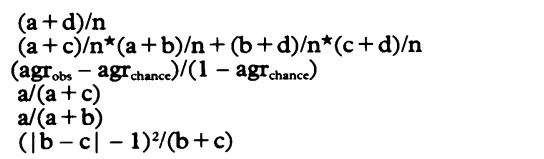 } \\
\hline
\end{tabular}

and the questionnaire ranged from two months to one year and four months. As detailed interviews would be redundant for mothers who did not have a job or who worked in jobs without chemical or physical exposure, only mothers who worked in occupations with a potential for exposure to chemicals or radiation were actually interviewed. This group included healthcare workers, cleaners, hairdressers, workers in industry and transport, and agricultural workers.

A set of interviews was specifically designed for each of the following 10 occupations: nurses, laboratory assistants, dental assistants, pharmaceutical assistants, physiotherapists, hairdressers, cleaners, printers, agricultural occupations, and occupations in industry or transport. In each interview, traditional work history questions on job title, industry, company name, number of hours worked, and tasks performed were asked first. Subsequently, detailed standardised questions developed by the investigators on the basis of occupational hygiene information were used to inquire about every occupational task that had possibly been performed and about the associated use of chemicals and radiation, the frequency of the activity or the exposure, the use of protective devices, and exposure through the proximity of colleagues. For example, hairdressers were asked whether they applied hair sprays, what type of hair spray they used (with propellant gas or pump sprays), how often they applied hair dyes, and whether they had to prepare hair dyes themselves. Workers in the printing industry were asked whether they had to refill the ink supply and wash the ink rollers. At the end of each interview, the checklist used in the postal questionnaire was shown to find any agents that might have been missed. Detailed questions were asked again for the agents that were reported on the checklist. The period of interest ranged from two weeks before conception until six weeks after conception, calculated from the duration of pregnancy that was reported in the questionnaire.

The exposures from the interview were classified into 23 categories. For each exposure category, the information that was obtained was coded into two variables. The first variable concerned the exposure that the women themselves reported during the interview, which was coded dichotomously (variable $\mathrm{A})$. The second variable, indicating the level of exposure, was assessed by professional judgement of the investigators on a four point scale (high, moderate, low, and no exposure) and was based on the frequency of exposure, the type of protective equipment used, and exposure through colleagues. Eventually, the variable for level of exposure was dichotomised into no exposure versus any level of exposure (variable B) because of comparability with the postal questionnaire and small numbers.

In the analyses, only those exposure categories were included that were identically defined in the questionnaire and the interview (anaesthetics, antineoplastic drugs and antibi- 
Table 2 Characteristics of study population

\begin{tabular}{|c|c|}
\hline & $\begin{array}{l}\text { Women }(n=121) \\
n(\%)\end{array}$ \\
\hline $\begin{array}{l}\text { Case-control status: } \\
\text { Cases } \\
\text { Controls }\end{array}$ & $\begin{array}{l}55(45.5) \\
66(54.5)\end{array}$ \\
\hline $\begin{array}{l}\text { Age at interview: } \\
20-29 \\
30-39 \\
\geq 40 \\
\text { Education } \star\end{array}$ & $\begin{array}{l}20(16 \cdot 5) \\
85(70 \cdot 2) \\
15(12 \cdot 4)\end{array}$ \\
\hline $\begin{array}{l}\text { Low } \\
\text { Middle } \\
\text { High }\end{array}$ & $\begin{array}{l}35(29 \cdot 4) \\
64(53 \cdot 7) \\
20(16 \cdot 8)\end{array}$ \\
\hline $\begin{array}{l}\text { Occupation: } \\
\text { Healthcare workers } \\
\text { Cleaners } \\
\text { Hairdressers } \\
\text { Industry and transport workers } \\
\text { Agricultural workers }\end{array}$ & $\begin{array}{l}71(58 \cdot 7) \\
16(13 \cdot 2) \\
8(6 \cdot 6) \\
15(12 \cdot 4) \\
11(9 \cdot 1)\end{array}$ \\
\hline
\end{tabular}

otics; disinfecting and sterilising agents; domestic cleaning agents; dyes and pigments; pesticides; dust; ionising radiation; and nonionising radiation). Firstly, the exposure data from the postal questionnaire were compared with the self reported interview data obtained by the personal interview (variable $\mathrm{A}$ ). Secondly, the data from the postal questionnaire were compared with the interview exposure data after assessment of exposure by the investigators (variable B). In both comparisons, the personal interview with detailed job specific and task specific questions was assumed to be the gold standard. The $\kappa$ coefficients $\left(\kappa_{\mathrm{A}}\right.$ and $\left.\kappa_{\mathrm{B}}\right)$ with $95 \%$ confidence intervals $(95 \% \mathrm{CIs})^{13}$ were calculated as measures of agreement corrected for chance, and sensitivity and positive predictive values as measures of validity and usefulness. Table 1 shows the formulas and a $2 \times 2$ table used for calculation of these measures. High sensitivity for a specific agent indicates that little underreporting of that agent in the questionnaire exists; a high positive predictive value is interpreted as little overreporting in the questionnaire. To test whether both forms of misclassification (overreporting and underreporting) occurred randomly or whether systematic overreporting or underreporting occurred, McNemar's tests were calculated. A low $P$ value means a high probability of

Table 3 Comparison of exposure from postal questionnaires with self reported exposure in job specific interview (variable A)

\begin{tabular}{|c|c|c|c|c|c|c|c|c|}
\hline \multirow[b]{2}{*}{ Exposure categories } & \multicolumn{2}{|c|}{ Exposed $(n=121)$} & \multirow[b]{2}{*}{$\begin{array}{l}\text { Prevalence } \\
\text { (\%) }\end{array}$} & \multirow[b]{2}{*}{$\kappa(95 \% C I)$} & \multirow[b]{2}{*}{$\begin{array}{l}\text { Sensitivity } \\
(\%)\end{array}$} & \multirow{2}{*}{$\begin{array}{l}\text { Positive } \\
\text { predictive } \\
\text { value (\%) }\end{array}$} & \multicolumn{2}{|c|}{ McNemar } \\
\hline & $\begin{array}{l}++ \\
-+\end{array}$ & $\begin{array}{l}+- \\
--\end{array}$ & & & & & $\chi^{2}$ & $P$ value \\
\hline $\begin{array}{l}\text { Anaesthetics, antineoplastic } \\
\text { drugs, and antibiotics }\end{array}$ & $\begin{array}{r}33 \\
1\end{array}$ & $\begin{array}{l}20 \\
67\end{array}$ & 28 & $0.63(0.50$ to 0.77$)$ & 97 & 62 & $23 \cdot 0$ & 0.00 \\
\hline Disinfecting and sterilising agents & $\begin{array}{r}41 \\
3\end{array}$ & $\begin{array}{l}40 \\
37\end{array}$ & 36 & $0.35(0.22$ to 0.48$)$ & 93 & 51 & $41 \cdot 5$ & 0.00 \\
\hline Domestic cleaning agents & $\begin{array}{r}65 \\
3\end{array}$ & $\begin{array}{l}43 \\
10\end{array}$ & 56 & $0.16(0.03$ to 0.28$)$ & 96 & 60 & $64 \cdot 1$ & 0.00 \\
\hline Dyes and pigments & $\begin{array}{r}10 \\
5\end{array}$ & $\begin{array}{l}10 \\
96\end{array}$ & 12 & $0.50(0.28$ to 0.72$)$ & 67 & 50 & $4 \cdot 3$ & $0 \cdot 04$ \\
\hline Pesticides & $\begin{array}{l}5 \\
1\end{array}$ & $\begin{array}{r}3 \\
112\end{array}$ & 5 & $0.70(0.42$ to 0.98$)$ & 83 & 63 & 1.5 & $0 \cdot 22$ \\
\hline Grain, hay, paper, and textile dust & $\begin{array}{l}11 \\
16\end{array}$ & $\begin{array}{l}19 \\
75\end{array}$ & 22 & $0.20(0.00$ to 0.39$)$ & 41 & 37 & 0.5 & 0.49 \\
\hline Ionising radiation & $\begin{array}{l}8 \\
0\end{array}$ & $\begin{array}{l}15 \\
98\end{array}$ & 7 & $0.46(0.25$ to 0.68$)$ & 100 & 35 & $19 \cdot 0$ & 0.00 \\
\hline Non-ionising radiation & $\begin{array}{l}5 \\
6\end{array}$ & $\begin{array}{l}11 \\
99\end{array}$ & 9 & $0.29(0.05$ to 0.54$)$ & 45 & 31 & $2 \cdot 7$ & $0 \cdot 10$ \\
\hline
\end{tabular}

$++=$ Exposed according to postal questionnaire and personal interview; $+-=$ exposed according to postal questionnaire alone; $-+=$ exposed according to per sonal interview alone; - $-=$ non-exposed according to postal questionnaire and personal interview.

Table 4 Comparison of exposure from postal questionnaires with exposure assessed by investigators in job specific interview (variable B)

\begin{tabular}{|c|c|c|c|c|c|c|c|c|}
\hline \multirow[b]{2}{*}{ Exposure categories } & \multicolumn{2}{|c|}{ Exposed $(n=121)$} & \multirow[b]{2}{*}{$\begin{array}{l}\text { Prevalence } \\
(\%)\end{array}$} & \multirow[b]{2}{*}{$\kappa(95 \% C I)$} & \multirow[b]{2}{*}{$\begin{array}{l}\text { Sensitivity } \\
(\%)\end{array}$} & \multirow{2}{*}{$\begin{array}{l}\text { Positive } \\
\text { predictive } \\
\text { value (\%) }\end{array}$} & \multicolumn{2}{|c|}{ McNemar } \\
\hline & $\begin{array}{l}++ \\
-+\end{array}$ & $\begin{array}{l}+- \\
--\end{array}$ & & & & & $\chi^{2}$ & Pvalue \\
\hline $\begin{array}{l}\text { Anaesthetics, antineoplastic } \\
\text { drugs, and antibiotics }\end{array}$ & $\begin{array}{r}28 \\
0\end{array}$ & $\begin{array}{l}25 \\
68\end{array}$ & 23 & $0.56(0.42$ to 0.70$)$ & 100 & 53 & $15 \cdot 4$ & 0.00 \\
\hline Disinfecting and sterilising agents & $\begin{array}{r}32 \\
2\end{array}$ & $\begin{array}{l}49 \\
38\end{array}$ & 28 & $0.27(0.15$ to 0.38$)$ & 94 & 40 & $30 \cdot 1$ & 0.00 \\
\hline Domestic cleaning agents & $\begin{array}{r}39 \\
1\end{array}$ & $\begin{array}{l}69 \\
12\end{array}$ & 33 & $0.09(0.02$ to 0.15$)$ & 98 & 36 & $33 \cdot 1$ & 0.00 \\
\hline Dyes and pigments & $\begin{array}{l}8 \\
3\end{array}$ & $\begin{array}{l}12 \\
98\end{array}$ & 9 & $0.45(0.22$ to 0.68$)$ & 73 & 40 & $1 \cdot 1$ & $0 \cdot 30$ \\
\hline Pesticides & $\begin{array}{l}3 \\
1\end{array}$ & $\begin{array}{r}5 \\
112\end{array}$ & 3 & $0.48(0.12$ to 0.83$)$ & 75 & 38 & $0 \cdot 3$ & 0.62 \\
\hline Grain, hay, paper, and textile dust & $\begin{array}{l}11 \\
14\end{array}$ & $\begin{array}{l}19 \\
77\end{array}$ & 21 & $0.23(0.03$ to 0.42$)$ & 44 & 37 & $0 \cdot 1$ & $0 \cdot 74$ \\
\hline Ionising radiation & $\begin{array}{l}2 \\
0\end{array}$ & $\begin{array}{l}21 \\
98\end{array}$ & 2 & $0.13(0.00$ to 0.30$)$ & 100 & 9 & $13 \cdot 1$ & 0.00 \\
\hline Non-ionising radiation & $\begin{array}{l}3 \\
5\end{array}$ & $\begin{array}{r}13 \\
100\end{array}$ & 7 & $0.18(0.00$ to 0.42$)$ & 38 & 19 & 0.9 & 0.33 \\
\hline
\end{tabular}
$++=$ Exposed according to postal questionnaire and personal interview; $+-=$ exposed according to postal questionnaire alone; $-+=$ exposed according to per-
sonal interview alone; $--=$ non-exposed according to postal questionnaire and personal interview. 

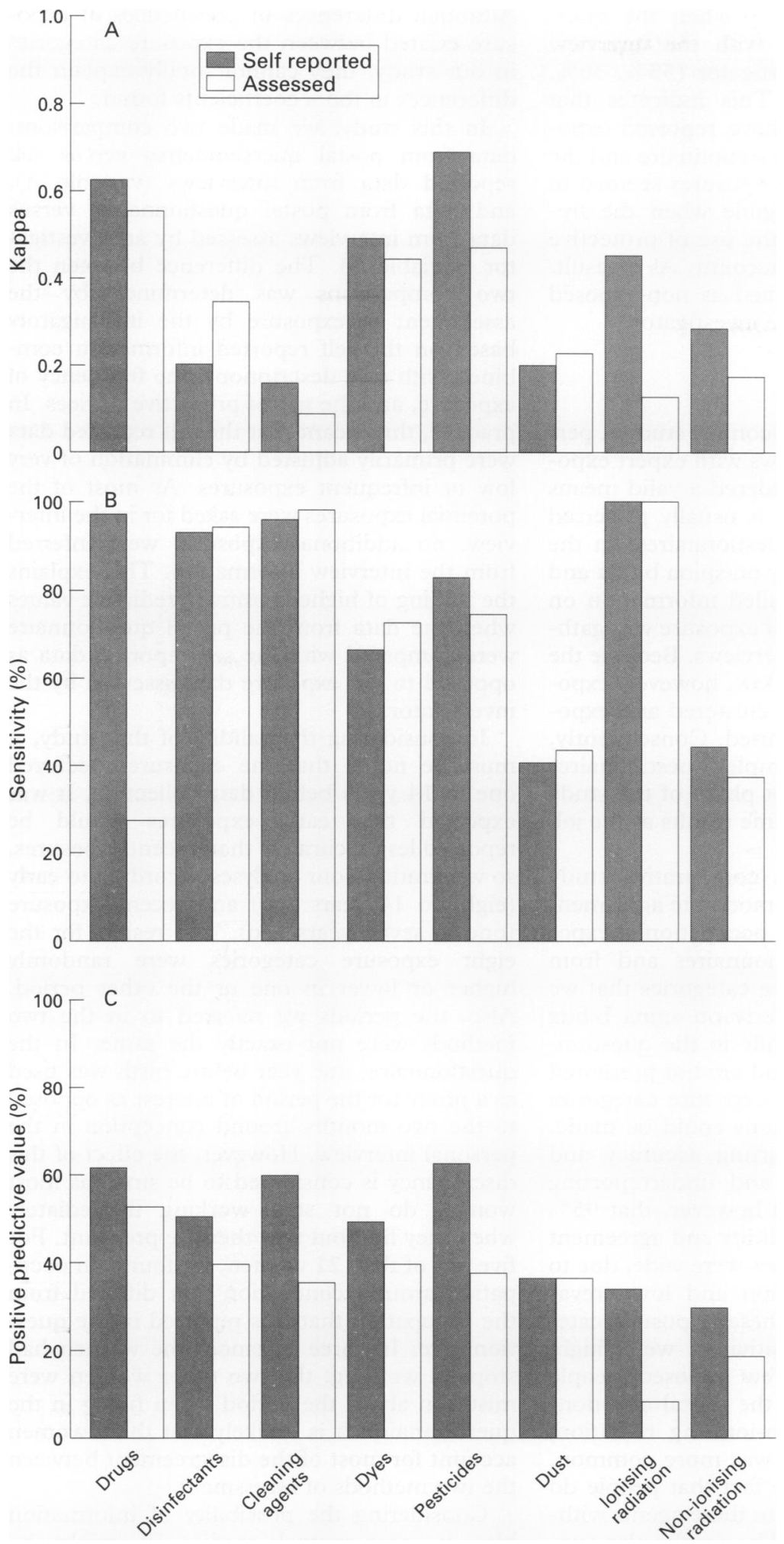

(A) $\kappa$ coefficients of questionnaire $v$ interview information: self reported data as a gold standard compared with investigator assessed data as a gold standard. (B) Sensitivity of questionnaire $v$ interview information: self reported data as a gold standard compared with investigator assessed data as a gold standard. (C) Positive predictive values of questionnaire $v$ interview information: self reported data as a gold standard compared with investigator assessed data as a gold standard. study population. Of the women, $70 \%$ were between 30 and 40 years of age at the time of the interview; the same percentage of women had at least 10 years of education. More than half of the women worked in health care.

Table 3 shows the results of the comparisons made between the postal questionnaires and the self reported information on exposure from the job specific interviews, and table 4 shows the results of the comparison between the postal questionnaire and the exposure assessed from the interviews by an investigator. In the first column (the $2 \times 2$ subtables) of both tables the numbers of exposed people according to questionnaire and interview are given. Also, the differences between the results in table 3 and table 4 are visually presented in the figure. The figure (A) depicts the results of the $\kappa$ coefficients. Most of the coefficients are $<0.4$, so agreement is considered to be poor. This implies that the respondents were not very accurate in reporting occupational exposure by means of a postal questionnaire. The figure also shows that large variability existed between the different categories. For instance, typical occupationally used agents, such as anaesthetics and drugs by healthcare workers $\left(\kappa_{\mathrm{A}}=0.63, \kappa_{\mathrm{B}}=0.56\right)$ and pesticides by agricultural workers $\left(\kappa_{\mathrm{A}}=\right.$ $\left.0.70, \kappa_{\mathrm{B}}=0.48\right)$ gave better results than categories such as dust $\left(\kappa_{\mathrm{A}}=0 \cdot 20, \kappa_{\mathrm{B}}=0 \cdot 23\right)$ or cleaning agents $\left(\kappa_{\mathrm{A}}=0 \cdot 16, \quad \kappa_{\mathrm{B}}=0 \cdot 09\right)$. Many women might have considered common household dust or the use of domestic cleaning agents at home as a workplace exposure while filling out the questionnaire. Because the $\kappa$ coefficient was influenced by the prevalence of exposure, ${ }^{14}$ which differed between the exposure categories in this study (tables 3 and 4) comparisons between the $\kappa$ coefficient must be interpreted with care.

The sensitivity (figure (B)) ranged between $38 \%$ and $100 \%$. For drugs and anaesthetics, disinfecting agents, domestic cleaning agents, and ionising radiation, sensitivity was almost $100 \%$. This indicates that women who were exposed to these agents could be reasonably well detected by the questionnaire. However, for dust and non-ionising radiation sensitivity was low, which may reflect the fact that some people do not realise that they are exposed to these agents. It is clear that the sensitivity did not change much when the data assessed by the investigator instead of the self reported data were used as the gold standard.

The fifth columns in tables 3 and 4 show that the positive predictive values ranged between $9 \%$ and $63 \%$. In all exposure categories the positive predictive value was low and lower than the sensitivity. The difference was significant with McNemar's test for half of the categories. Overreporting in the questionnaire was thus common. The highest positive predictive values were found for anaesthetics and drugs (62\%), cleaning agents $(60 \%)$, and pesticides $(63 \%)$, when the postal questionnaire was compared with the self reported interview data (figure (C)). However, in concordance with the results of the $\kappa$ coefficients, these positive predictive val-
All 121 women who were invited for the interview ( 55 cases and 66 controls) in this part of the study participated. Table 2 presents the frequencies of some characteristics of this 
ues decreased considerably when the questionnaire was compared with the interview data assessed by an investigator (53\%, 36\%, and $38 \%$ respectively). This indicates that sometimes women may have reported exposures consistently in the questionnaire and the interview, whereas these exposures seemed to be non-existent or negligible when the frequency of exposure and the use of protective devices were taken into account. As a result, these women were classified as non-exposed in the data assessed by the investigator.

\section{Discussion}

In population based case-control studies, personal job specific interviews with expert exposure assessment are considered a valid means of data collection, which is usually preferred over self administered questionnaires. In the second phase of our study on spina bifida and parental occupation, detailed information on exposure and frequency of exposure was gathered by means of such interviews. Because the exposure prevalence was low, however, exposure categories had to be clustered and exposure levels were dichotomised. Consequently, we wondered if the simple questionnaires which we used in the first phase of the study would have yielded the same results as the job specific interviews.

The results from this comparative study show that, overall, low to moderate agreement exists between data on occupational exposures from postal questionnaires and from interviews. Some exposure categories that we inquired about in our study on spina bifida were not defined identically in the questionnaire and the interview and are not presented in this paper. Within the exposure categories for which exact comparisons could be made, large differences in reporting accuracy and degree of overreporting and underreporting existed. It must be noted however, that $95 \%$ CIs of the measures of validity and agreement of some exposure categories were wide, due to the small study population and low prevalences of exposure for these exposure categories. In general, sensitivities were high, indicating that only a few exposed people were missed when using the postal questionnaire. For dust and non-ionising radiation, however, underreporting was more common. This might be due to the fact that people do not realise their exposure to these agents without detailed prompting. The results also suggest low positive predictive values and thus much overreporting in the postal questionnaire. In particular, exposure to cleaning agents and dust, which are common domestic exposures, was heavily overreported. The questionnaire may not have clearly indicated that the questions concerned only work exposures. Also, some women may have considered household cleaning agents and dust as workplace exposures. However, typical occupationally used agents, such as agents used by healthcare workers (anaesthetics, antineoplastic drugs, and antibiotics) and by agricultural workers (pesticides) show better agreement.
Although differences in prevalences of exposure existed between the exposure categories in our study, they cannot totally explain the differences in the $\kappa$ coefficients found.

In this study, we made two comparisons: data from postal questionnaires versus self reported data from interviews (variable $\mathrm{A}$ ), and data from postal questionnaires versus data from interviews assessed by an investigator (variable B). The difference between the two comparisons was determined by the assessment of exposure by the investigators based on the self reported information combined with task descriptions, the frequency of exposure, and the use of protective devices. In practice, this meant that the self reported data were primarily adjusted by elimination of very low or infrequent exposures. As most of the potential exposures were asked for in the interview, no additional exposures were inferred from the interview information. This explains the finding of higher positive predictive values when the data from the postal questionnaire were compared with the self reported data as opposed to the exposure data assessed by the investigator.

In considering the validity of this study, it must be noted that the exposures occurred one to 14 years before data collection. It was expected that early exposures would be reported less accurately than recent exposures, so we stratified our analyses according to early (eight to 14 years ago) and recent exposure (one to seven years ago). The results for the eight exposure categories were randomly higher or lower in one or the other period. Also, the periods we referred to in the two methods were not exactly the same. In the questionnaire, one year before birth was used as a proxy for the period of interest as opposed to the two months around conception in the personal interview. However, the effect of this discrepancy is considered to be small as most women do not stop working immediately when they find out that they are pregnant. For five out of the 121 women, we found an occupation around conception that differed from the occupation that was reported in the questionnaire. In three instances the women had stopped working; the two other women were mistaken about the period when filling in the questionnaire. It is unlikely that these women account for most of the disagreement between the two methods of assessment.

Considering the possibility of information bias in case-control studies, it might be expected that differences in reporting exist between cases and controls. Therefore, we stratified our analyses on agreement and validity according to case-control status. As the $\kappa$ coefficients, sensitivities, and positive predictive values were randomly higher and lower for cases than controls in the eight exposure categories, we think that no evidence for differential misclassification of information exists. However, numbers in subgroups were small, leading to unstable estimates.

For efficiency reasons only people with occupations with a high potential for exposure were selected for an interview. Although this 
interviewed study population of 121 women was of primary interest in the present study, it was not representative of the total study population for the prevalence of exposure. In the total study population with a lower prevalence of exposure, the cell distributions in the contingency table would shift towards a less symmetric distribution of agreement, leading to a lower $\kappa \cdot .^{14} 15$ The effect of variation in the disagreements, which is likely to occur when the sensitivity and specificity of the questionnaire remains the same, is smaller. Also, the positive predictive value decreases with decreasing prevalence of exposure.

Few studies have examined different methods of assessment of exposure used in population based case-control studies. Eskenazi and Pearson ${ }^{10}$ compared questionnaires with clinical interviews and suggested that self administered questionnaires can be used to obtain valid information on occupation and occupational exposure from pregnant women. However, the time between initial and subsequent data collection in their study averaged three weeks, and the period of interest was at most nine months before data collection. Most investigators express a preference for more detailed and job specific methods of data collection..$^{1-5}$

In conclusion, we found that the use of postal questionnaires has a high potential for misclassification, although results differ between the various categories of chemical agents. Therefore, self administered questionnaires are not an alternative for job and task specific interviews combined with assessment of exposure by an occupational hygienist. We argue that job and task specific interviews should be performed whenever possible in population based case-control studies which examine exposures that must be assessed retrospectively. If other methods such as postal questionnaires are used, overestimation of exposure might occur. It should be noted that when exposure prevalences are low, overre- porting resulting in a decrease in positive predictive value has a larger influence on the validity and the power of the study than underreporting of exposure. ${ }^{1617}$

This work was financially supported by the Prinses Beatrix Fonds.

1 Goldberg $M$, Hémon D. Occupational epidemiology and assessment of exposure. Int $\mathcal{F}$ Epidemiol 1993;22(suppl 2):S5-9.

2 Gérin M, Siemiatycki J, Kemper H, Bégin D. Obtaining occupational exposure histories in epidemiologic casecontrol studies. $\mathcal{F}$ Occup Med 1985;27:420-6.

3 Gérin M, Siemiatycki J. The occupational questionnaire in retrospective epidemiologic studies: recent approaches in
community-based studies. Appl Occup Environ Hyg 1991; 6:495-501.

4 Stewart W, Stewart P. Occupational case-control studies: I Collecting information on work histories and workrelated exposures. Am f Ind Med 1994;26:297-312.

5 Stewart P, Stewart W. Occupational case-control studies: II Recommendations for exposure assessment. Am $\mathcal{F}$ Ind Med 1994;26:313-26.

6 Rona RJ, Mosbech J. Validity and repeatability of selfreported occupational and industrial history from patients in EEC countries. Int $\mathcal{f}$ Epidemiol 1989;18: patients 9 .

7 Baumgarten M, Siemiatycki J, Gibbs G. Validity of work histories obtained by interview for epidemiologic purposes. Am $\mathcal{F}$ Epidemiol 1983;118:583-91.

8 Joffe $M$. Validity of exposure data derived from a structured questionnaire. Am $\mathcal{f}$ Epidemiol 1992;135:564-70.

9 Teschke K, Kennedy SM, Olshan AF. Effect of different questionnaire formats on reporting of occupational expoquestionnaire formats on reporting of
sures. Am $\mathcal{F}$ Ind Med 1994;26:327-37.

10 Eskenazi B, Pearson K. Validation of a self-administered questionnaire for assessing occupational and environmental exposures of pregnant women. Am $\mathcal{F}$ Epidemio 1988;128:1117-29.

11 Blatter BM, Roeleveld N, Zielhuis GA, Mullaart RA, Gabreëls FJM. Spina bifida and parental occupation. Epidemiol 1996;7:188-93.

12 Blatter BM, Roeleveld N, Zielhuis GA, Gabreëls FJM, Verbeek ALM. Maternal occupational exposure during preonancy and the risk of spina bifida. Occup Environ Med 1996;53:80-6.

13 Cohen J. A coefficient of agreement for nominal scales. Psychological Measurement 1960;20:37-46.

14 Armstrong BK, White E, Saracci R. Monographs in epidemiology and biostatistics vol 21. Principles of exposure measurement in epidemiology. Oxford: Oxford University Press, ment in epide

15 Lantz $C$, Nebenzahl E. Behavior and interpretation of the $\kappa$ statistic: resolution of the two paradoxes. $\mathcal{F}$ Clin Epidemiol 1996;49:431-4

16 Stewart WF, Correa-Villaseñor A. False positive exposure errors and low exposure prevalence in community-based case-control studies. Appl Occup Environ Hyg 1991;6: $534-40$.

17 Hemminki K, Lindbohm ML, Kyyrönen P. Validity aspects of exposure and outcome data in reproductive studies. $\mathcal{F}$ Occup Environ Med 1995;37:903-7. 